\title{
DOMESTICIDAD Y FAMILIA: AMBIGÜEDAD Y CONTRADICCIÓN EN LOS MODELOS DE FEMINIDAD EN EL FRANQUISMO ${ }^{1}$
}

\author{
EIDER DE DIOS FERNÁNDEZ \\ Universidad del País Vasco
}

Recibido: 24/03/2014

Aceptado: 12/05/2014

\section{Resumen}

La instauración de la dictadura franquista significó la consolidación de un modelo de familia que, mediante la combinación de elementos católicos y falangistas, se convirtió en la base legitimadora del nuevo régimen. Aunque en teoría se trataba de sujetos subordinados, el papel desempeñado por las mujeres en la estructura familiar fue muy destacado. El espacio de la influencia y no del poder fue el destinado para ellas. Este artículo se plantea como principal objetivo conocer la manera en que estas mujeres interiorizaron los postulados de género del régimen y cómo reaccionaron ante ellos. La utilización de la fuente oral, siempre rica en matices, nos guiará en el proceso de construcción subjetiva de cuatro mujeres pertenecientes a distintas clases sociales y que, como hijas, novias, esposas y madres, aprendieron a ser mujeres en el franquismo.

Palabras clave: Género, franquismo, subjetividad, familia, domesticidad, fuente oral.

\begin{abstract}
The establishment of Franco's dictatorship meant the consolidation of a family model which combined catholic and 'falangista' elements and legitimized the new regime. The role played by women in the family/familial structure was very important, despite the subordinate role women played in society; influence and not power was the area reserved for them. The main objective of this paper is a consideration of the way in
\end{abstract}

1. Este artículo se enmarca en el proyecto que lleva a cabo el Grupo de Investigación «La experiencia de la sociedad moderna en España 1870-1990», financiado por la U.P.V./ EHU (código GIU08/15) dirigido por José Javier Díaz Freire. 
which these women interiorised, and had to deal with, the gender postulates of the regime. The use of the oral source, always rich in nuance, will lead us in the process of subjective understanding of four women belonging to different social classes who learnt to be women as daughters, girlfriends, wives and mothers under Francoism.

Keywords: Gender, Francoism, subjectivity, family, domesticity, oral source.

Feminismo/s 23, junio 2014, pp. 23-46 
Durante el franquismo, el discurso dominante insistía en menospreciar las capacidades femeninas y en exaltar tan solo una de las dimensiones vitales de la mujer, la maternidad. Esta capacidad de generar nuevos y disciplinados individuos se convertía en su única aportación a la sociedad y el único fin de su existencia². Es por ello que el análisis de la figura de la madre de familia resulta tan enriquecedora para los estudios del franquismo. A través de este artículo trataremos de reflexionar sobre el rol del «ama de casa» en la estructura matrimonial y en el ámbito familiar e intentaremos mostrar la evolución del significado de la maternidad a lo largo de la dictadura.

Con este fin utilizaremos como fuente principal el testimonio oral de cuatro mujeres que nacieron y forjaron su identidad a lo largo del franquismo ${ }^{3}$. La fuente oral nos permitirá conocer cómo los sujetos se conciben a sí mismos y, a partir de las categorías discursivas que tienen a su alcance, cómo interpretan la realidad. Es esta subjetividad lo que hace de la historia oral una fuente tan fecunda porque, no sólo nos ayuda a complementar la información aportada por las fuentes tradicionales, sino que también nos ayuda a comprender el significado de éstas ${ }^{4}$.

Las cuatro mujeres que hemos seleccionado tienen entre 66 y 85 años y pertenecen a distintas clases sociales, pero nos centraremos en las experiencias que comparten en cuanto al aprendizaje y la enseñanza de esa domesticidad. Gracias a su testimonio podremos darnos cuenta de los cambios que se dieron en la manera de interpretar la maternidad de cuando ellas fueron hijas a cuando se convirtieron en madres de familia. Analizaremos en qué medida el modelo ideal de mujer chocaba con las maneras de mujeres reales

2. Molinero, Carme. «Silencio e invisibilidad: la mujer durante el primer franquismo». Revista de Occidente 224 (2000), p. 77.

3. Cuatro entrevistas puede resultar un número escaso pero este artículo se desarrolla en base a metodologías cualitativas. Además, este proyecto se inscribe dentro de un cómputo de unas treinta entrevistas de las cuales hemos elegido los testimonios que más aspectos nos muestran de la subjetividad femenina en el franquismo y la enseñanza de la feminidad.

4. Llona GonZÁlez, Miren. «Memoria e identidades. Balance y perspectivas de un nuevo enfoque historiográfico», en Cristina Borderías (coord.): La historia de las mujeres: perspectivas actuales, Icaria, Barcelona, 2009, pp. 355-390. 
y nos daremos cuenta de que, a pesar de la atmósfera represiva, estas mujeres fueron capaces de conseguir pequeños espacios, si no de reivindicación, sí de disconformidad con respecto al modelo de mujer que les era impuesto.

\section{Desde pequeñita y con afición}

El franquismo intentó, no sin éxito, producir un vínculo intrínseco entre mujer y domesticidad. Se trataba de definir unas fronteras a modo de muros infranqueables que dividían esferas que teóricamente no debían imbricarse: la esfera pública y la doméstica. Como Ana Aguado señaló, la división dicotómica del mundo exterior y del mundo del hogar no llegó nunca a desarrollarse plenamente ${ }^{5}$. No obstante, la dictadura, en su empeño por conseguirlo al menos en sus dos primeras décadas, legisló a favor de esta división.

La mujer debía ser, ante todo, ama de casa y, con este fin, la Ley de Educación Primaria de 1945 en su artículo 11 establecía currículums diferenciados para niños y niñas. El sistema educativo franquista preparaba a las niñas «para la vida en el hogar, artesanía e industrias domésticas» ${ }^{6}$. Las niñas debían ser «pequeñas amitas de casa» había que convencerlas de que su espacio era el «hogar», un hogar burgués idílico y muy a menudo inalcanzable para la mayoría de mujeres ${ }^{7}$. De hecho, desde 1944 y a pesar de las quejas de diversos sectores educativos se extendió al bachillerato las «Enseñanzas de Hogar». El empeño de la Sección Femenina de que las niñas $y$, en este caso concreto las bachilleras, recibieran estos estudios estribaba en que la madre de familia española debía realizar muchos oficios en el interior de su hogar. Debía ser cocinera, doncella, costurera, bordadora,

5. AGUADO, Ana: «La historia de las mujeres como historia social», en María Isabel Del Val et al. (coords.): La historia de las mujeres: una revisión historiográfica, Valladolid, Universidad de Valladolid, 2004, pp. 57-71.

6. Morcillo GómEZ, Aurora. «Españolas con, contra, bajo, (d)el franquismo», en V.V.A.A.: Desacuerdos.Sobrearte, políticasyesferapúblicaenelEstadoespañol,vol.7,2012.p.42.<http:// www.macba.cat/uploads/publicacions/desacuerdos/textos/desacuerdos_7/Aurora_ Morcillo_Gomez.pdf>, consultado el 13-05-2013.

7. Al igual que ocurrió en los años veinte, la representación correcta de moralidad de clase media exigía a las señoras ser domésticas. El horizonte de estas señoritas era convertirse en una buena señora de su casa. Sus estudios se basaban en el aprendizaje de habilidades que reforzaran su carácter doméstico. La realización de actividades remuneradas en el exterior del hogar constituía la negación de la domesticidad, la negación de la esencia de la feminidad de las clases medias. LlonA, Miren. Entre señorita y garçonne. Historia oral de las mujeres bilbainas de clase media (1919-1939), Málaga, Universidad de Málaga, 2002, pp. 27-28. 
zurcidora, planchadora, recadera, enfermera, contable, economista, maestra e higienista ${ }^{8}$.

Otro de los empeños de la Sección Femenina fue la introducción del deporte en la enseñanza femenina. La gimnasia como práctica deportiva con asiduidad fue criticada por la Iglesia católica, pero la sociedad en general la toleraba mientras estuviera subordinada a subrayar o desarrollar mejor las funciones vinculadas a la mujer y que no redujera su «feminidad». A las niñas, y también a las mujeres, se les reservaba deportes basados más en la habilidad que en la fuerza, privilegiando deportes de carácter individual que evitaran el contacto físico. El cuerpo de la mujer estaba profundamente sexualizado y ello conllevaba que se la conceptualizara como una criatura de naturaleza impura, por ello el deporte debía ser realizado tanto para mejorar sus aptitudes de madre como para regular la sexualidad femenina ${ }^{9}$.

De todas formas, la escuela era entendida en muchas ocasiones como un lugar de tránsito, un lugar donde se enseñaba a las niñas «las cuatro reglas básicas», cierta cultura general y se las preparaba para el ejercicio de "sus labores ${ }^{10}$. Generalmente, las niñas estudiaban hasta los 12 o 14 años como es el caso de nuestras entrevistadas. Angustias ${ }^{11}$ cuenta con tristeza cómo tuvo que dejar la escuela, a pesar de que "era de las primeras de la clase», sus padres prefirieron que ella dejara de estudiar en lugar de sus hermanos para encargarse de las tareas domésticas:

Unas veces era ella la primera, otras veces yo, la primera o la segunda con la Ángeles. Me gustaba estudiar, mucho, mucho, mucho. Me costó mucho disgusto que no me dejaran estudiar. Pero mi madre era muy mayor y no podía hacer ya las cosas y entonces yo le hacía falta a la madre, para hacer las cosas

8. MANRIQUE ARRIBAS, Juan Carlos, «La familia como medio de inclusión de la mujer en la sociedad franquista ». Hispania Nova 7 (2007), p. 23.

9. ROCA i GiRONA, Jordi. De la pureza a la maternidad, la construcción del género femenino en la posguerra española, Madrid, Ministerio de Educación y Cultura, 1996, pp. 185-186.

10. Para el estudio de los manuales escolares recomendamos RISUEÑO JURADO, Virginia: «La maternidad vista a través de las imágenes de los manuales escolares. El caso de España, Francia y Holanda (1901-1940)», en Gloria A. Franco Rubio (ed.): Debates sobre la maternidad desde una perspectiva histórica (siglos XVI-XX), Barcelona, Icaria, 2010, pp.127-145.

11. Angustias Sales Pujalte, 83 años, ama de casa, nacida en Casas Bajas, Valencia. Angustias nació en el seno de una familia de clase media baja. Mientras sus cuatro hermanos varones tuvieron la posibilidad de estudiar, a ella la obligaron a dejar la escuela a los 14 años para ocuparse de su padre, su madre y sus hermanos mayores después. Al casarse comienza a combinar el cuidado de la casa materna con el de su nueva familia, tarea a la que consagrará toda su vida. En la actualidad es viuda y reside en Teruel al igual que sus cuatro hijos. Entrevista realizada por Eider de Dios y Raúl Mínguez, Teruel a 7 de enero de 2012.

Feminismo/s 23, junio 2014, pp. 23-46 
de la casa y para los animales... y para todo, y para traer alfalfe y el agua, y a lavar. Y como para todo hacía falta ya, pues ya no quisieron mis padres que yo estudiara ${ }^{12}$.

Angustias fue la única de los cuatro hermanos que no fue a la universidad. Ella tuvo que relevar a su madre en la casa familiar e incluso trasladarse con sus hermanos cuando tuvieron que cambiar de población para continuar con sus estudios. Se convirtió así en el ama de casa de sus hermanos hasta que se casaron. Angustias considera que se sacrificó para que el resto de hermanos pudieran continuar sus sueños y que, a partir de ese momento, adquirió unas responsabilidades que ni hoy en día puede eludir.

El abandono de la escuela no fue un fenómeno aislado en las niñas de clase obrera y media; sólo una minoría de mujeres fue impulsada en el primer franquismo a seguir estudiando ${ }^{13}$. Incluso entre familias de la burguesía, muy frecuentemente no se incitaba a las hijas a que siguieran estudiando. Este es el caso de Genoveva ${ }^{14}$, cuyos padres prefirieron que se quedara en casa a ayudar a la familia y así «aprender para cuando ella tuviera casa propia». Genoveva, a diferencia de Angustias, no guarda un recuerdo traumático de este hecho sino que lo naturaliza. Incluso se muestra satisfecha de todos los conocimientos que adquirió bajo la enseñanza de su madre, conocimientos que en un futuro no sólo le sirvieron para gobernar su propia casa, sino también una manera de procurar ingresos.

A partir del momento en el que se abandonaba la escuela eran las madres de familia quienes debían complementar la labor educacional. Las madres de

12. Para comprender las dificultades domésticas de las amas de casa en el primer franquismo recomendamos IGLESIAS HERNÁNDEZ, María Luisa: «El ama de casa y el espíritu de sacrificio en el franquismo», en Laura Benadiba (comp.): Historia oral: fundamentos metodológicos para reconstruir el pasado desde la diversidad, Rosario, SurAmérica ediciones, 2010, pp. 253-269.

13. Martina RodrígueZ, $\mathrm{M}^{\mathrm{a}}$ Victoria y RodríGUez Gallardo, Ángel, «De compromisos e igualdades. Historia y sociopolítica de las mujeres universitarias gallegas durante el franquismo», Comunicación presentada en el VIII Encuentro Internacional de Investigadores del Franquismo, celebrado en Barcelona el 21 y 22 de noviembre de 2013.

14. Genoveva Aguirre de la Villa, 74 años, jubilada, nació en Santa María de Getxo (Vizcaya) donde sigue residiendo. La familia de Genoveva pertenecía a la alta burguesía vizcaína, ella era la séptima de diez hermanos y hermanas. Cuando llegó a la adolescencia, como su hermana mayor se había ido de monja a un convento y Genoveva no parecía una estudiante aplicada, su padre decidió que dejara de estudiar para ayudar a su madre en el manejo de su casa y del servicio. Al casarse continuó con su papel de ama de casa que había aprehendido de adolescente, fue cuando sus cuatro hijos tuvieron edad de elegir carrera y profesión cuando decide ponerse a trabajar para poder dar ejemplo a sus hijos. Entrevista realizada por Eider de Dios, en Getxo a 13 de enero de 2012. 
familia tenían la responsabilidad de modelar las conciencias de sus hijos como futuros españoles. La familia constituía el microcosmos del régimen franquista donde la autoridad era ejercida por el padre de familia pero donde el cuidado maternal era crucial para mantener una sociedad estable y ordenada. Era el deber de la madre de familia educar a su descendencia cristianamente $e^{15}$. A pesar de que programáticamente la mujer adquiriera un papel secundario en la sociedad, durante el primer franquismo se dignificó su papel a través de función gestora en el hogar; de esta manera se dignificaba también el mito de la Santa Madre y la maternidad como un continuo martirio. La dignificación iba de la mano de la influencia que la madre demostraba en las relaciones familiares y en la transmisión de valores formativos, relacionados con la ideología, la religión y el civismo ${ }^{16}$; a su vez, debía convertirse en el modelo ideal al que debían aspirar sus hijas. Este discurso ejemplificante, esta mitificación de la figura de la madre lo considero como un efecto balsámico: las llagas del martirio, los constantes desvelos, la clausura forzada en un mundo pequeño ${ }^{17}$ de la que nos hablaba Carme Molinero pretendía quedar subsanada con la dignificación de la figura materna.

No eran siempre las madres quienes enseñaban a sus hijas a convertirse en «verdaderas» mujeres. Durante la dictadura fue común que los hijos de familias con escasos recursos acudieran a seminarios o conventos. Elisa ${ }^{18}$ con 12 años no dudó en dejar su aldea de Burgos para irse a un convento en La Rioja donde estaría hasta los 18 años. Durante ese tiempo aprendió hacer muchas

15. MorCiLlo, Aurora: «El género en lo imaginario. El "ideal católico femenino" y estereotipos sexuados bajo el franquismo», en Mary Nash (ed.): Represión, resistencias, memoria. Las mujeres bajo la dictadura franquista, Granada, Comares Historia, 2013, pp.71-90.

16. MANRIQUE ARRIBAS, Juan Carlos. Op. cit., pp. 12-13, 18, 26.

17. Expresión de Carme Molinero en MOLINERO, Carme. «Mujer, franquismo, fascismo. La clausura forzada en un 'mundo pequeño'», en Historia social, 30 (1998), pp. 97-117.

18. Elisa Robledo Sáez, 72 años, jubilada. Elisa nació en una aldea de Burgos en una familia de pequeños agricultores, al acabar la escuela primaria se fue a un convento. Afirma que las niñas de su pueblo sólo tenían dos opciones, dedicarse al campo o ir de monja, ella tomó esta segunda opción. A los 18 años decidió que le gustaba demasiado la vida familiar para dedicarse al noviciado, y es entonces cuando una mujer le propuso ir a servir a su casa a Bilbao y aceptó. Al casarse siguió limpiando casas, y sólo salió del mercado laboral durante dos años al tener a dos de sus hijos muy seguidos. Se siente hoy en día muy satisfecha por haber sabido combinar el trabajo como empleada de hogar y el de madre de familia, sin que ninguno de los trabajos haya perjudicado al otro. Además de esas actividades, ha sido catequista y tiene una conciencia cívica muy activa, ha estado luchando para conseguir mejoras en su barrio como la instalación de una guardería y una escuela, autobuses que comunicaran con el centro bilbaíno, entre otras muchas cosas. Entrevista realizada por Eider de Dios, en Bilbao a 27 de abril de 2010 .

Feminismo/s 23, junio 2014, pp. 23-46 
labores e incluso ejerció de maestra, ya que a ella se le otorgó el cuidado de los párvulos. Para Elisa el paso por el convento constituyó una experiencia muy enriquecedora ya que pudo adquirir una disciplina de trabajo y capacidades organizativas que la han acompañado en su vida como mujer trabajadora y madre de familia numerosa.

Otra de las posibles «escuelas de formación» la constituía el servicio doméstico. El servicio doméstico durante el franquismo fue uno de los nichos laborales femeninos más importantes y, a su vez, constituía una estrategia migratoria de mujeres pobres de áreas rurales a la ciudad. Un ejemplo de ello lo encontramos en María Luisa ${ }^{19}$ que al cumplir los 14 años se fue desde su aldea de León a servir en la capital. Esta vez era el ama de casa de la familia a la que debía servir quien debía enseñar a María Luisa cómo se organizaba una casa. La visión que María Luisa tiene sobre esta etapa de su vida como interna en el servicio doméstico dista mucho de la opinión que Genoveva, como empleadora, tenía sobre el servicio doméstico en régimen de internado. Mientras la primera lo consideraba como un «amaestramiento» de la muchacha rural y como forma de explotación, la segunda lo aprecia como una verdadera «escuela de aprendizaje», el mejor recurso de las mujeres pobres de «afinarse» y adquirir cierta sofisticación ${ }^{20}$.

\section{2. «Para ver si encuentro un novio, el más bonito de España»}

La enseñanza iba dirigida a la conversión de las niñas en mujeres y no podían convertirse en verdaderas mujeres sin pasar por el altar. El matrimonio podía ser con un hombre de un estatus económico-social similar al de estas mujeres o con Dios, pero no cabía otro destino o por lo menos no sería el camino más deseado. En el siguiente fragmento podemos observar la inexistencia de otras vías de desarrollo personal ajenas al matrimonio además del compendio de los atributos que debían mostrar las muchachas casaderas:

Puedes ser feliz perdida en la suave niebla de un sueño bien encauzado. No sueñes con cosas descabelladas, muchacha, que tales sueños, si bien podrán procurarte breves momentos de loca dicha, no sabrán evitarte la crueldad

19. María Luisa Romero nació en la década de 1940 en una aldea de León. Estuvo estudiando hasta que a los 14 años se fue de interna a la capital. Más adelante, se trasladaría a Bilbao donde trabajaría de interna hasta contraer matrimonio. Entonces, trabajaría en una carnicería que organizarán entre su marido y ella. Cuando la carnicería pasa por problemas económicos, volverá al trabajo doméstico en donde ha estado hasta ahora. Entrevista realizada por Eider de Dios en Bilbao a 29 de abril de 2010.

20. DIOS FERNÁNDEZ, Eider de. « «Las que tienen que servir» y las servidas. La evolución del servicio doméstico en el franquismo y la construcción de la subjetividad femenina». Revista Historia Autónoma 3 (2013), pp. 97-111. 
de un amargo despertar. Piensa en que la felicidad en todas las épocas y circunstancias, tiene más de sonata que de sinfonía. (...) Evita el ocio si quieres evitar el tedio. (...) Quieres casarte ¿verdad? Es muy natural. Pero mientras estás soltera y a nadie te debes sino a ti misma, mientras puedes disponer libremente de tus horas, adquiere conocimientos, sé un poquillo curiosa, aprende todo cuanto debes saber para llegar dignamente al venturoso desenlace de tu novela: el matrimonio. Es un pequeño esfuerzo que te hará más feliz que en cualquier diversión y que hallará su recompensa en la gratitud del hombre que te lleve al altar. Finalmente, cuida de tí misma. La mujer joven tiene el derecho y el deber de agradar ${ }^{21}$.

Las muchachas podían soñar, pero el sueño debía ser uno determinado; entre líneas se intuía que debía soñar con «un buen marido y una gran familia». Al igual que Carmen Martín Gaite nos hablaba de que en la posguerra no sólo se precisaba el ahorro económico sino también el ahorro de energías reivindicativas y por supuesto sexuales ${ }^{22}$, el texto nos sugiere un ahorro onírico. La reducción de sueños conllevaba la reducción de expectativas. Se precisaban muchachas con los pies bien enterrados, que supieran bien dónde se hallaban los límites incluso del deseo y que se prepararan para momentos de felicidad momentáneos y no continuados. El ocio también debía reducirse, daba lugar al vicio, al vacío y al tedio; la mejor opción ante el tiempo libre era preparase, incluso intelectualmente, para el matrimonio. Había que esforzarse para que la recompensa fuera un buen marido. Pero no sólo debían ser buenas receptoras de sabiduría, su obligación era también convertirse en un bello recipiente. Debían resultar «apetecibles», a las mujeres durante la dictadura se les negaba una identidad sexual, no debían ser sujetos sexuales, en cambio, sí que se les reconocía la sensualidad, una sensualidad limitada, pero que permitiera que los varones se sintieran atraídos por ellas ${ }^{23}$. Indudablemente, la obra de la que procede el fragmento, al igual que la mayoría de revistas femeninas que se publicaron en el franquismo, estaba dedicada a las mujeres de las clases medias y altas. Este hecho se constata cuando tenemos en cuenta la interpretación que se hace del tiempo, dando a entender que la tenencia de horas muertas formaba parte de la vida de las muchachas. Sin embargo, las muchachas de la clase trabajadora trabajaban dentro y fuera de casa con lo que rara vez tenían opción al ocio. Incluso entre las muchachas de clases más acomodadas, como Angustias o Genoveva, el tiempo libre era muy limitado si tenemos en cuenta que el tiempo de ellas era el tiempo de la casa, las amas

21. Almanaque de la madre de familia, Barcelona, T.G. Roviera editor, 1950, p. 21.

22. MARTín GAITE, Carmen. Usos amorosos de la postguerra española. Barcelona, Anagrama, 1987, pp. 13-14.

23. Incidiremos en este tema más adelante.

Feminismo/s 23, junio 2014, pp. 23-46 
de casa no disponían de tiempo propio porque tenían que estar a disposición de los demás.

Asimismo, una de las opciones más recomendables para aprovechar el escaso tiempo libre con el que contaban era la preparación del ajuar matrimonial o el «arreo». María Antonia, por ejemplo, contaba, no sin cierta ironía, cómo ella y sus compañeras del servicio doméstico utilizaban los pequeños ratos en los que no recibían órdenes de sus señores: «no sabías con quién te ibas a casar pero llevabas años cosiendo para él».

Una de las mayores críticas que realizan las entrevistadas cuando tratamos temas relacionados con el noviazgo durante las décadas de los cincuenta y sesenta, y por supuesto las anteriores, es la desinformación.

¡Porque te cuentan cada cosa las de mi edad...! -confiesa Elisa- Pues eso, todo era pecao (sic), todo era sucio. Y con los chicos casi era, como de miedo más que de que de otra cosa y siempre muy recatadas, estarías deseando que te dijera un chico algo pero tú de insinuarte nada (Ríen). Te casabas virgen, por supuesto y la que no estaba virgen ya estaba marcada. Antes, fíjate, decir que te vas a vivir con el novio, eso era... a mí me habrían echao (sic) mis padres de casa. Y encima que no te informaban de nada, que no, que tú te lo tenías que discurrir por, por la vida misma, pero «ten cuidao (sic) con los chicos...», pero no te decían nada ni sabías lo que pasaba ni nada. Es que era así. No, no sabías. Así que tenías un miedo "¡Ay madre!, ¿pues esto?, ¿qué pasará?»(Ríen).

Resulta muy curioso comprobar cómo Elisa describe los códigos de relaciones de género de su juventud. Se las enseñaba a que desconfiaran de los chicos pero no se les explicaba las razones por las que debían temerles. Elisa se queja de cómo su madre o personas cercanas no pudieron enseñarles las maneras en las que tenían de relacionarse un hombre y una mujer, incluso cómo podían quedarse embarazadas. Se gobernaba con el miedo, el miedo a la reprobación y al aislamiento, a la etiqueta constante, al que fuera considerada como una «fresca». Se les negaba su propia sexualidad, era el hombre quien debía dar el primer paso, no debía invertirse el orden. Pero Elisa va más allá de la crítica al momento, se queja de que muchos de esos preceptos subsisten en las mujeres de su generación.

Como sabemos, no todas las mujeres se casaban vírgenes y muchas mujeres pudieron disfrutar de su sexualidad contradiciendo al discurso oficial. Era común la expresión «se han casado de penalti» para señalar a las parejas que se casaban bajo la certeza de que la muchacha estaba embarazada y se iba a quedar al descubierto «la prueba del delito». A pesar de que muchas fueron las parejas que llegaron al matrimonio habiendo tenido relaciones sexuales, el peso discursivo era tal que incluso hoy en día cuesta encontrar informantes 
que puedan hablar de estos temas abiertamente. A Angustias, una mujer tradicional de profundas raíces católicas, le cuesta contar que antes de casarse ya se había besado con el que luego sería su marido: «ientonces era mucho pecado!» por ello se confesaba cada vez que los novios se encontraban, intentaba expiar su culpa.

Aun y todo, no debemos confundir esta pretendida inocencia o candidez como sinónimo de inconsciencia en cuanto a las decisiones vitales se refiere. Todas las muchachas eran sabedoras de que la elección del marido marcaría sus vidas, por ello debían cerciorarse, en la medida de lo posible, de la conveniencia del novio para la vacante de marido ${ }^{24}$. Es Angustias quien nos describe qué motivos le llevaron a abandonar una relación:

Cuando estaba en la mili me escribió, -relata Angustias- me decía que no fuera al baile ni a la misa. A mí me gustaba ir a misa los domingos. Yo creo que ese Juan Miguel debió de ser celoso y de todo. ¡Ah!, y también me pedía que su madre la debía tener con él siempre. Demasiadas cosas. Yo le dije un día: «Juan Miguel, veo que no eres tan listo como me parecías porque, si fueras listo, no me hubieras dicho todas estas cosas porque entonces hubiera ido engañada, quizás a lo mejor nos hubiéramos casado y luego hubiera sabido todas estas cosas que me dices ahora. Pero como me las has dicho a tiempo, pues hemos terminado, así que no me llames, ni me escribas ni quiero saber ya nada más de ti». Y él aún insistió, e insistió pero ya nada.

Angustias no duda en rechazar a Juan Miguel, le parece celoso y posesivo pero se alegra de haberse enterado a tiempo de su manera de ser. No duda en insultar a la inteligencia de Juan Miguel porque de lo contrario hubiera insultado a la suya propia. No le parecía de recibo el que le impidiera acudir a la misa y al baile, la mayor ilusión de Angustias y los únicos espacios de asueto que tenía. En el caso de los bailes, la imposición venía de la mano de la concepción que se tenía de ellos durante el franquismo, como algo peligroso donde el propio ambiente podía incitar a la laxitud en las formas ${ }^{25}$. Bien es cierto que el baile funcionaba como el mejor expositor del mercado matrimonial, era de allí donde se forjaban gran parte de las parejas ${ }^{26}$. Tampoco le parecía justo que la impidiera acudir a misa. La iglesia como espacio de reunión del pueblo podía

24. MuÑoz Ruiz, María del Carmen. Mujer mítica, mujeres reales: las revistas femeninas en España 1955-1970, tesis doctoral, Universidad Complutense de Madrid, 2002, disponible en http://biblioteca.ucm.es/tesis/ghi/ucm-t26317.pdf (última consulta 3-02-2014), p. 218.

25. PiÉROla, Gemma. «Aspectos del discurso moral de la Iglesia sobre la población femenina navarra en el Franquismo». Gerónimo de Uztariz, 16 (2000), pp. 43-55.

26. Dios FERNÁNDEZ, Eider de, «Perfiles de las Trabajadoras de Hogar en el Desarrollismo Vizcaíno», Comunicación presentada en el X Congreso de la Asociación de Historia Contemporánea, Santander 16-17 de septiembre de 2010, publicación en CD. 
funcionar también como punto de encuentro entre jóvenes, algo que, según Juan Miguel, Angustias debía evitar. Nuestra entrevistada reconoce cómo todas las exigencias de Juan Miguel se habrían convertido en imposiciones en el caso de que se hubieran casado, sabía que en el matrimonio habría tenido un papel subyugado y que todas las «sugerencias» de Juan Miguel se hubieran convertido en preceptos, y por ello como soltera decidió no continuar con esta relación a pesar de las insistencias.

\section{La madre de familia}

Como adelantábamos líneas atrás, en el matrimonio se estipulaba una posición totalmente desigualitaria. Con la mejora del Código Civil impulsada por Mercedes Formica y aprobada el 14 de abril de 1958, se dieron algunos cambios positivos en la situación legal de la mujer en el matrimonio ${ }^{27}$. Se abogaba por una mujer tradicional aunque se le otorgaba ahora ciertas mejoras dentro del matrimonio. No obstante, se dejaba claro que, dentro del matrimonio, iba a ser el marido el que ejerciera la autoridad ${ }^{28}$. Pese al aperturismo legal que en materia de género se desarrolló desde esa fecha, las mujeres no eran capaces, como nos cuenta María Luisa, ni siquiera de disponer de los bienes adquiridos por y para el matrimonio:

Cuando nos hicimos novios Javi y yo, y ya nos pensamos casar, -nos cuenta María Luisa- yo sabía que este piso lo iban a vender y como tenías tus ahorros y te habías mentalizao (sic) de que había que comprarse un piso, y, y eso, y no malgastar el dinero, pues yo me lo compré y vinimos a vivir aquí. $\mathrm{Y}$ después, mi marido era carnicero y compramos aquí en el barrio una carnicería, y por aquello de estar interna y no pedir permiso, y no poder salir...Pues mi marido fue al notario y puso la carnicería a nombre de él, cuando yo el piso lo había puesto al nombre de los dos ¡Pero es que las escrituras se podían haber hecho por la tarde y haber firmao (sic) yo! No, como estaba él solo... y los notarios no sé si conscientemente o inconscientemente hacen unas escrituras a nombre de él, y a las 6, 8 horas que fui yo allí ya no se podía hacer nada,

27. Una interesante visión de la reforma se encuentra en el número de junio de Teresa. En éste se entremezclaban alusiones que hacían referencia a la modernización, «la reforma más revolucionaria», y a la vez se dejara claro que no se realizaban cambios en la supremacía del marido: «Una inteligente reforma del Código que mejora la situación jurídica de la mujer. Se mantiene intacto el principio de autoridad marital, tan necesario para la buena marcha de la familia», en Teresa, 58 (junio 1958), pp. 26-27.

28. La reforma sustituyó el concepto «casa del marido», con el que se definía la vivienda común y que daba por hecho que era propiedad del varón, por «hogar conyugal». De esta manera, la mujer separada podía quedarse con el domicilio familiar. La dote también fue eliminada. FRANCO, Rosario. ¿Eternas menores? Las mujeres en el franquismo. Biblioteca Nueva, Madrid, 2007, pp. 118-127.

Feminismo/s 23, junio 2014, pp. 23-46 
decían que ya había que hacer otras escrituras ¡E ir al banco a hacer papeles y que no pudieras hacer nada si no iba tu marido!... De normal no tenía nada, ¡era que vamos...! Y yo les protestaba a los de la Caja de Ahorros, y ellos «la Ley es así». No, no, a mí es que eso me ha repugnao (sic) toda la vida.

Puede parecer un hecho aislado que una chica de servicio como María Luisa pudiera comprarse un piso en una época en la que existía un importante problema de vivienda, sin embargo, no se trata de una excepción. Si el ideal femenino de posguerra estaba muy ligado al ahorro, las chicas de servicio lo encarnaban como nadie, trabajaban de internas en muchas ocasiones para poder ahorrar de cara a un futuro y muchas de ellas fueron capaces de acceder a un piso a diferencia de sus novios ${ }^{29}$. Este pasaje resulta muy revelador porque muestra muchos aspectos de la mujer española ante la Ley. Por una parte encontramos la inexistencia de regulaciones laborales en el servicio doméstico y las implicaciones que conlleva un régimen interno que supone estar disponible las 24 horas. Por otra parte, encontramos la diferencia en cómo concibe María Luisa el piso que ella había comprado como la residencia conyugal y no duda en incluir a su marido en las escrituras, y cómo su marido concibe el negocio del que dependería la familia como suyo propio. Aunque su mujer fuera a trabajar allí, él era el carnicero, la profesionalidad recaía en él y en cambio María Luisa era el ama de casa que «ayudaba». La propia sociedad del momento, encarnada en los notarios, lo concibe también de esa manera. Finalmente, María Luisa se queja de la dependencia que tenía de su marido a la hora de realizar cualquier trámite burocrático o económico siendo ella una mujer capaz de encargarse de aquellas tareas sola sin necesidad de testaferros $^{30}$. Sin embargo, hemos de subrayar que María Luisa era una mujer

29. Un ejemplo de esta mentalidad de ahorro lo encontramos en testimonio de Pura Sánchez en AHOA Archivo de la Memoria, http://www.ahoaweb.org/resultados.php?ent=311 consultado 02-02-2014

30. Es la Ley de 2 de julio de 1975 la que introduce sustanciales reformas sobre la situación de la mujer en el Código Civil y en el Código de Comercio. Dota de un nuevo significado al domicilio conyugal, genera una nueva regulación de la nacionalidad de los esposos y de los derechos y deberes recíprocos de los cónyuges. La mujer deja de ser considerada un mero satélite del marido y deja de estar supeditada a la licencia marital, es decir, ya no tendría que pedir permiso a su marido para emplearse. El artículo 64 del C.C. fue modificado y quedó establecido que ambos cónyuges podrían disfrutar recíprocamente de sus bienes. Los artículos 1387 y 1388 dejan a la mujer disponer y litigar sobre sus bienes parafernales sin consentimiento de su marido. En el artículo 57 se regulaban los derechos y deberes recíprocos en el matrimonio sin que se redujera la capacidad de obrar de ambos. Y en democracia continuaran las modificaciones de cara a una mayor igualdad de los cónyuges ante la Ley, pero hasta ese momento, como hemos visto, muchas de las decisiones de las mujeres estaban supeditadas legalmente a la voluntad de sus maridos. En VAlLÉs AMORES, María Luisa. «La posición jurídica

Feminismo/s 23, junio 2014, pp. 23-46 
consciente de su posición de inferioridad y de dependencia y lejos de naturalizar su situación se rebela y protesta ante la desigualdad. Como María Luisa, creo que es posible pensar en la existencia mujeres corrientes conscientes de su situación que se mostraban disconformes con la misma.

A pesar de que la voluntad de la mujer en el discurso oficial estuviera supeditada al marido, era este mismo discurso el que las dotaba de cierta capacidad de mando. Nos referimos a la influencia. Se produce así una división entre poder e influencia; la influencia es la habilidad de persuadir o manipular a otros, no se basa en la fuerza sino en el carisma o en la autoridad moral. La influencia es la habilidad de canalizar el poder de otros y desde una óptica antropológica el poder se ligaba a los hombres y la influencia a las mujeres ${ }^{31}$. Se trata de lo que podríamos denominar la metáfora del cuello y la cabeza, entendiendo al hombre como el cabeza de familia y la cabeza visible y a la mujer como el cuello que sustenta esa cabeza. Las decisiones son tomadas por la reflexiva cabeza pero es el cuello quien hace el gesto, quien afirma o niega y quien sustenta la cabeza. Las mujeres contaban con la capacidad de influir en las decisiones de su marido, la influencia se consideraba algo lícito, algo «natural» de la feminidad española ${ }^{32}$. La búsqueda del poder era algo antifemenino, revertir el orden «natural» de las cosas, utilizando un poder que solo les correspondía a los hombres. En cambio, la influencia era la fuerza legítima de las mujeres, constituía un «arma de mujer» autorizada: «Un día te casarás $y$, al igual que todas las mujeres (que de esto no se entere tu novio) serás tú quien mande en casa» ${ }^{33}$. Pero este manejo debía hacerse con cautela y "por debajo de la mesa» sin levantar sospecha y sin que el marido lo percibiera. Una reflexión más extensa sobre hasta qué medida las mujeres que vivieron su juventud en el franquismo sienten que han podido llevar las riendas de su hogar merecería una investigación ulterior.

El destino del matrimonio era la descendencia, de hecho, no era un fin en sí mismo, constituía el medio para llegar a la procreación. Son los hijos

de la mujer a través de las reformas del derecho de familia», Feminismo/s 8, (2006), pp. 123-124.

31. GILmORE, David D. «Men and Women in Southern Spain: "Domestic Power" Revisited», en American Anthropological Association, New Series, 92-4 (1990), pp. 955.

32. En nuestra opinión la manera de funcionar de la Sección Femenina y su forma de conseguir medios o alcanzar reivindicaciones tuvo mucha relación con esta imagen de la feminidad y la utilización de la influencia. Esta idea nos surge a partir del análisis que hace Inbal Ofer de la forma de actuar del gabinete jurídico de dicha institución, en OFER, Inbal, Señoritas in blue. The making of a female political elite in Franco's Spain, Sussex, Brighton, 2010, p. 82.

33. Nuestra Casa. Revista del Montepío Nacional del Servicio Doméstico, 1 (diciembre de 1959), p. 8 
los que confirman el vínculo, mientras estos no llegaban la unidad conyugal vivía en una especie de provisionalidad. A la mujer se la entendía como un ser unidimensional cuya esencialidad era la maternidad y de quien únicamente se reconocía su aspecto biológico. Sólo a través de la maternidad alcanzaba su auténtica y obligada finalidad vital y su verdadero estatuto como persona ${ }^{34}$.

Nuestras entrevistadas fueron madres durante el segundo franquismo; en esa época se estableció una diferencia con respecto a la forma en la que a sus propias madres se les había hecho entender su maternidad. Como dijimos, la maternidad en el primer franquismo era entendida como un servicio a la patria pero los cambios en el gobierno de la dictadura, la influencia de estilos e ideas provenientes de Europa y de Estados Unidos, sobre todo a través de las películas, abrieron nuevas perspectivas en el concepto de familia. La maternidad seguía siendo un fin en sí mismo, pero había dejado de concebirse como un sacrificio para la patria, se comenzó a entender como un medio para conseguir la felicidad personal ${ }^{35}$.

El índice de felicidad o de malestar de las amas de casa en relación al tamaño de su familia, propuesto por FOESA en 1970, dibuja una atmósfera reveladora. Dicho informe señalaba la relación incómoda entre el desarrollo económico y la modernización política, que constituirá una de las paradojas de las últimas décadas del franquismo. Significativamente, en el estudio de la felicidad, ésta se incrementaba en familias pequeñas y medianas. La familia grande y numerosa por una parte, y la familia mínima a su vez, encontraban las mayores tasas de infelicidad. Las mayores cotas de ansiedad y depresión se localizaban en esos dos límites. Sobre todo, demostraba denunciando la sobrecarga de tareas que suponía ser responsable de una familia numerosa. En el ámbito de la familia mínima, afloraban sentimientos por la falta que generaba el no cumplir con el rol maternal y la soledad que eso conllevaba ${ }^{36}$. María Luisa nos muestra las dificultades con las que se encontraba para hallar esa pretendida felicidad con la interminable jornada de la madre de familia:

Él trabajaba pero hay otros que trabajaban, y colaboraban -cuenta María Luisa- Yo siempre, siempre he tirao (sic) de la carga hasta que no puedes más, una pasada. De haber tenido que hacer de todo, de todo y no hacerte ellos nada, nada. Todo al morrito, todo al morrito, hasta la ropa, todo, todo. Y yo me he sentido, no frustrada, pero no haber sabido haber reivindicao (sic) como mujer otra colaboración. Y también, no he disfrutao (sic) de mis hijos tanto como ahora que cuando eran pequeños, porque fue muy agobiante.

34. ROCA I GIRONA, Jordi, Op. cit., pp. 224-227.

35. MANRIQUE ARRIBAS, Juan Carlos, Op. cit., p. 14.

36. Romo PARra, C., El desorden de la identidad..., Op. cit., pp. 102-103.

Feminismo/s 23, junio 2014, pp. 23-46 
Aparte de tener que ir yo constantemente a la carnicería a todo, era tener tres hijos...Y muchas veces estabas, incluso, de mal humor, cabreada, impotente. Y yo cuando venía a las 11 había días que estaba ya que me subía por las paredes, y claro, buena relación... iqué coño vas a tener buena relación! La relación sí, pero, ¡hala tira!

María Luisa hoy en día se queja a su marido de esa paternidad ausente que mantuvo hacia sus hijos. Como señala Aurora Morcillo, en el discurso nacional católico los españoles debían ser mitad soldado y mitad monjes pero a las mujeres se las exigía ser completamente esposas y completamente madres ${ }^{37}$. Esta compatibilización ya de por sí agotadora, resulta aún más agobiante si tenemos en cuenta que María Luisa trabajaba también fuera de casa y debía cumplir una doble jornada y una doble invisibilidad ${ }^{38}$. En un momento como el actual, en el que el reparto de las tareas domésticas está más repartido, María Luisa culpabiliza a su marido y a sus hijos de no haberse responsabilizado del cuidado de la casa. Pero a su vez, se siente culpable de no haber podido disfrutar de su propia maternidad. Al igual que ocurría con los consultorios sentimentales de las revistas femeninas, es en el testimonio oral donde encontramos las fricciones entre los modelos ideales y la realidad social. Además, contrariamente al discurso oficial, el cumplimiento del modelo de mujer socialmente aceptado, como vemos, no garantizaba necesariamente la felicidad. Esto sucede porque el modelo de comportamiento que se exigía a las mujeres durante la dictadura suponía la anulación como persona en función de los deseos e intereses de otros, tanto del esposo y de los hijos, como de la sociedad en general ${ }^{39}$.

\section{El sexo de los ángeles}

Para el antropólogo Jordi Roca i Girona resulta muy definitorio de la política de género del régimen el bolero de Machín Corazón Loco en el que se enfrentan, por una parte, una mujer sacralizada, la «esposa y madre a la vez», y, por otra, una mujer sexualizada, la amante, «el complemento de mis ansias». Para el autor dicho bolero refleja la bipolaridad con la que el régimen trataba a la mujer y la escisión que realizaba entre maternidad y la sexualidad. Sin embargo, estimamos que esa bipolaridad se daba en la propia forma de

37. MorCillo, Aurora. El género en lo imaginario... Op. cit., p.78

38. BORDERÍAS, Cristina. Entre líneas, trabajo e identidad femenina en la España Contemporánea: la compañía Telefónica, 1924-1980. Barcelona, Icaria, 1993.

39. MuÑoz Ruiz, María del Carmen. «La construcción de las relaciones de género en el franquismo y sus conflictos. Los consultorios sentimentales», Arenal 10-2 (2003), pp. 220-221. 
interpretar la figura de la esposa como virgen y objeto de deseo al mismo tiempo ${ }^{40}$. Podríamos decir que, a pesar de los estrictos preceptos de la Iglesia, el régimen propugnaba una suerte de ángel sexuado. Como señaló María del Carmen Muñoz Ruiz, el modelo de mujer esposa-madre-ama de casa resultaba muy útil a la dictadura porque, entre otras cosas, realizaban un trabajo no remunerado en un Estado donde los servicios sociales estaban muy reducidos. Y el hecho de que pudieran aportar a sus maridos el «descanso del guerrero» constituía un importante elemento de canalización del malestar social en un contexto político dictatorial muy represivo ${ }^{41}$. Este «descanso del guerrero» lo debemos entender también en su vertiente sexual. Se precisaba una mujer complaciente en las relaciones sexuales con su marido, al que no podía negarle el deseo, se entendía que debía estar siempre dispuesta para prestarse a esos impulsos. Además, en el discurso médico se la describía como un mero recipiente del acto sexual ya que sus órganos, se afirmaba, no necesitaban preparación previa ni el deseo sexual para realizar el acto sexual ${ }^{42}$. Así se resumían las «obligaciones» de alcoba en un manual de la Sección Femenina:

Debes tener un aspecto inmejorable a la hora de ir a la cama, si debes aplicarte crema facial o rulos para el cabello, espera hasta que él esté dormido, ya que eso podría resultar chocante para un hombre a última hora de la noche. En cuanto respecta a la posibilidad de relaciones íntimas con tu marido, es importante recordar tus obligaciones matrimoniales: si él siente la necesidad de dormir, que sea así, no le presiones o estimules la intimidad. Si tu marido sugiere la unión, entonces accede humildemente, teniendo siempre en cuenta que su satisfacción es más importante que la de una mujer. Cuando alcance el momento culminante, un pequeño gemido por tu parte es suficiente para indicar cualquier goce que hayas podido experimentar. Si tu marido te pidiera prácticas sexuales inusuales, sé obediente y no te quejes ${ }^{43}$. Es probable que tu marido caiga entonces en un sueño profundo, así que acomódate la ropa, refréscate y aplícate crema facial para la noche y tus productos para el cabello. Puedes entonces ajustar el despertador para levantarte un poco antes que él por la mañana. Esto te permitirá tener lista una taza de té para cuando despierte $e^{44}$.

40. Esto no contradice que existieran dos tipos de mujeres. De hecho, era común que los señoritos de clases medias se introdujeran sexualmente a través de mujeres de posición menos desahogada como prostitutas y criadas en lugar que con sus novias, consideradas «chicas decentes».

41. MuÑor Ruiz, María del Carmen. La construcción de las relaciones... Op. cit., pp. 221-222.

42. MANRIQUE ARRIBAS, Juan Carlos. Op. cit., p. 10.

43. Una obra de teatro actual, titulada El Manual de la buena esposa y compuesta por varios sketches relacionados con la evolución de la Sección Femenina, recoge este pasaje. Es una obra interesante para analizar el imaginario colectivo sobre dicha institución.

44. Sección Femenina, Economía doméstica para bachillerato y magisterio, Madrid, 1958.

Feminismo/s 23, junio 2014, pp. 23-46 
Incluso al final del día, después de una jornada agotadora, el ama de casa debía tener un aspecto radiante y nunca parecer cansada. Pero esta belleza tenía que parecer natural y todo acicalamiento debía realizarse en secreto. Primero había que parecer atractiva para que el marido pudiera sentir deseos sexuales. Después, una vez que el marido se hubiera dormido, la mujer tenía que levantarse y acicalarse en el baño colocándose los rulos si fuera necesario para que el marido a la hora del desayuno pudiera verla otra vez preciosa. Mientras a las mujeres se les exigía cierta sensualidad, una sensualidad tolerada para que sus maridos siguieran interesados en ellas, se negaba su sexualidad: no parecían tener deseo propio y de tenerlo debía estar sometido al del varón, no podían preocuparse de la satisfacción propia y para alentar la hombría de su pareja se les exigía fingir. En cierta medida, la sociedad responsabilizaba a las mujeres de que los maridos se masturbaran o que tuvieran relaciones ilícitas ya que «buscan fuera lo que en su casa no les dan» ${ }^{45}$. Por esta razón se las pedía que transigieran cualquier tipo de práctica sexual poco habitual. Se castigaba la iniciativa sexual femenina y el propio derecho al placer.

La sensualidad jugaba un papel muy importante a la hora de «mantener» al marido, se trataba de un ejercicio de «tirar el anzuelo y mantener el sedal $»^{46}$, la atracción debía mantenerse: "Cuando aceptaste ser su esposa, le diste una mujer que a él le gustaba. No cometas, ahora, pues, el fraude de darle otra distinta $»^{47}$. Era la mujer quien se daba al varón y no debía cometer fraudes con el cuidado externo de su persona, en la medida de lo posible debía mantener durante años la imagen de mujer con la que se había casado, no podía «echarse a perder». Buscando otro símil musical, podríamos decir que a las mujeres durante el franquismo se les exigía ser una especie de Carmen de

45. Al hilo de la lectura realizada y la reflexión sobre que los maridos insatisfechos acudían a recursos como la prostitución recomendamos La Descarriada (1973), película protagonizada por Lina Morgan. Cuenta la historia de una joven que por desavenencias económicas tiene se ve obligada a recurrir a la prostitución (aunque nunca la ejerce). En una de las escenas finales, el suegro y la mujer de uno de sus clientes acuden a ella para saber cuáles son los motivos que llevan al marido infiel a acudir a una prostituta. La prostituta da una clase magistral a la señora, una mujer de clase media. Entre otras cosas, le recomienda que a la hora de ir a la cama siempre debe ir arreglada y mostrarse dispuesta a desnudarse de forma erótica. Una vez acabado el acto, deberá acudir al baño para procurarse los cuidados estéticos necesarios y después regresar a la cama. El personaje de Lina Morgan advierte que si trata de esa manera a su marido nunca volverá a acudir a prostitutas.

46. En las revistas femeninas eran comunes las alusiones a la «pesca». Ejemplo en "pescar un buen marido», en Marisol El semanario de la mujer 217, (24-30 de marzo de 1958), s. n.

47. Almanaque de la madre de familia, p. 73.

Feminismo/s 23, junio 2014, pp. 23-46 
España, una mujer con «fuego en las pestañas» «pero cristiana y decente» ${ }^{48}$. Una mujer sensual pero que, como buena católica, no se deja llevar por los instintos, como la propia Carmen Sevilla, que encarnaba la dulzura que se apreciaba en el modelo católico de feminidad a la par que una gran picaresca en su forma de cantar e incluso de mirar a la cámara ${ }^{49}$.

Por todo lo que hemos comentado hasta ahora, podemos comprender que las mujeres que forjaron su carácter en el franquismo a menudo tienen una relación muy compleja con su sexualidad. Es bastante común, cuando nos referimos a métodos de anticoncepción que empezaron a darse a partir de los sesenta, que nos encontremos con una especie de ausencia del deseo sexual, como nos muestra Angustias:

Él sólo quería pasarlo bien y adelante, sin mirar las consecuencias. Yo tenía mucho miedo. Entonces acostumbré a acostarme tarde porque me quedaba rato y rato acostando a los hijos, para ver si se había dormido pero nunca se dormía. Pues le tenía miedo, de verdad. A lo último le cogí hasta asco. Me acuerdo que con mi cuñada fuimos al médico y salió la prueba de que estaba embarazada. Aún le estaba dando de mamar a Clemente y ya estaba otra vez embarazada (era su quinto hijo). (...) Y entonces el médico me dijo: «Esto no puede ser, ya tienes bastantes» «Pues ya sé que no puede ser pero, ¿qué hago? No puedo evitarlo. Bastante me toca luchar y llorar». Me recetó las píldoras, y gracias a las pastillas, ya no he tenido más hijos. Yo le decía a mi cuñada: «Milagros, que yo nunca he querido tomar cosas de esas», y ella me decía: «Tú tranquila, te lo ha mandado el médico». Ya lo sé que los curas estaban en contra pero a mí me lo había mandado el médico y yo siempre estuve tranquila, de verdad, estuve tranquila.

48. Esta manera de relacionar la imagen de la española ideal con Carmen de España nos surgió a partir de la lectura de: ANDReu Miralles, Xavier, «Y no la de Mèrimeè.... el mito romántico de España y la identidad nacional española», Comunicaciones del I Encuentro de Jóvenes Investigadores en Historia Contemporánea de la AHC, disponible en http://ifc.dpz.es/recursos/publicaciones/27/15/29. xavierandreu.pdf, última consulta el 6-02-2014.

49. La propia persona de Carmen Sevilla se entremezcla con los personajes que interpreta. Por una parte, resulta una mujer muy sensual y se muestra sabedora de ello y, por otra parte, hace públicas sus facetas domésticas que calificaba de tradicionales. Una muestra de ello lo encontramos en "Adiós al cine de Carmen Sevilla. 'Cariño Mío', y 'Baile en Capitanía' serán sus dos últimas películas porque se va a casar», en Teresa, n. 67 , julio de 1959. En dicho artículo defendía que dejaba de trabajar para dedicarse al papel más importante que había tenido hasta el momento, el de madre y esposa. Sin embargo, en el n. 15 de Nuestra Casa Revista del Montepío Nacional del Servicio Doméstico, correspondiente a febrero de 1962 aparecía en la portada con una imagen moderna conduciendo un gran deportivo. Más adelante, hacia 1969 intentó realzar su carrera cinematográfica con un nuevo registro a través de papeles más dramáticos y una estética pseudo-erótica convirtiéndose así en una de las pioneras del Destape.

Feminismo/s 23, junio 2014, pp. 23-46 
Este fragmento refleja muchos elementos concernientes a la vida sexual y a la reproducción. Encontramos otra vez el ejemplo de la paternidad poco responsable, de un hombre que no es capaz de comprender que sus actos tendrán consecuencias y que está deseoso de tener relaciones sexuales con su mujer. Por otro lado, tenemos a Angustias, que expone su vida sexual como algo totalmente traumático y que le genera repulsión. Estaba agotada de la crianza de sus cuatro hijos y, a pesar de ser una mujer muy católica y conservadora, decidió tomar la píldora anticonceptiva. Eso sí, para justificar que iba a usar un método prohibido por la Iglesia y para no sentirse culpable de su uso, necesita apoyarse en otra autoridad para justificar sus actos, el médico. Como era la palabra del médico y se trataba de motivos de salud, no debía plantearse mayores debates sobre tomarse o no la píldora.

Elisa mantiene una visión menos traumática de su sexualidad aunque comparte con Angustias que ella debía de ser quien frenara los impulsos de su marido para no tener más hijos.

Yo he sido bastante me dicen que adelantada a mi tiempo. Borra esto un poco, bueno, es que es un aspecto que también es de nuestra época igual es interesante también. (...) Y empecé a tomar la píldora antes de legalizarla. Yo enseguida pensé «Dios no puede querer esto, esto es un callejón sin salida». Y dije, «No. Yo creo que Dios no se mete en la alcoba. Lo que quiere Dios es que sea feliz, es que haga feliz a mi marido, que sea feliz con mis hijos y que esté a gusto» y nada, me liberé de maravilla, sí, sí, sí, sí.

Elisa, una mujer católica y catequista vinculada a grupos como la J.O.C., decide tomar la píldora porque creía que Dios pretendía que fuera feliz y ello conllevaba tener unas relaciones sexuales «sanas» sin lugar a miedos ni a culpabilidades. A finales de los sesenta y hasta principios de los noventa, la publicidad de los medios de comunicación pretendía mostrar que la introducción de productos como la moda prêt à porter, la comida enlatada y en especial los electrodomésticos habían facilitado la vida del ama de casa ${ }^{50}$. Estas nuevas creaciones se publicitaban como verdaderos medios de emancipación, pero resulta significativo cómo la verdadera revolución para Elisa, en lugar de lo que denomino la lavadora liberadora, fuera la píldora anticonceptiva. A pesar de que en un principio Elisa pide que en la edición se elimine este episodio, más adelante ordena que se transcriba la totalidad del episodio, sin censuras. Elisa a lo largo de su entrevista se dio cuenta de que a través de la píldora llegó a tomar una de las decisiones más relevantes de su vida. A

50. RebOllo EsPinOSA, María José y NúÑEZ GIL, Marina. «Tradicionales, rebeldes, precursoras: instrucción y educación de las mujeres españolas a través de la prensa femenina (1900-1970)», Historia de la educación. 26 (2007), p. 210. 
medida que fue evocando pasajes de su memoria, lejos de sentir pudor por lo relatado, se siente empoderada y satisfecha y por ello cree que su experiencia debe ser transmitida como parte de su historia y de muchas de las mujeres de aquella época.

\section{Conclusiones}

La dictadura franquista intentó generar un vínculo indeleble entre mujer y domesticidad. Según el discurso nacional-católico, la más grande, y única, función de la mujer española era la procreación y educación de individuos disciplinados. Si bien durante la posguerra, con la gran sangría demográfica, la maternidad se entendió como un sacrificio necesario para servir a la patria, los cambios que se produjeron en el país en la década de los cincuenta permitieron modificar la interpretación de la maternidad. Esta se convirtió en ese momento en la única vía con la que podían contar las españolas para que fueran felices. Sin embargo, como hemos comprobado, el cumplimiento del modelo de mujer propugnado, la triada de madre-esposa-ama de casa, no siempre llevó emparejada la felicidad.

A las niñas se las educaba para que en el futuro pudieran cumplir bien dicha tríada en la escuela mientras que en los hogares se las enseñaba «lo que una mujer debe ser». Las cualidades en las que fueron educadas eran la abnegación hacia la célula familiar, la humildad y la sumisión a las normas y a la autoridad paterno-marital. Se las exigía renunciar a su propia sexualidad a la par que se toleraba y se esperaba en ellas cierta sensualidad.

Bajo este clima de constricción podríamos pensar que las entrevistadas y las españolas en general se convirtieron en sujetos anulados y anegados en un océano de represión. Sí es cierto que hubo mujeres que no pudieron desarrollar sus expectativas de juventud y ello les causó una gran infelicidad, como es el caso de Angustias, cuya abnegación como ama de casa la obligó a dedicarse a sus hermanos, su marido, sus padres y sus hijos quedando prácticamente anulada como individuo. Sin embargo, muchas mujeres supieron encontrar las fisuras del ideal femenino y convertirse en las mujeres que quisieron ser. Genoveva, en lugar de sentirse disconforme con la decisión de sus padres en consagrarla a la casa, se siente muy orgullosa porque, cuando el modelo de mujer trabajadora se impuso, supo adaptarse a él. Vendió aspiradoras y montó su propia empresa de catering, es decir, utilizó su domesticidad o su domesticación para convertirse en una mujer trabajadora acorde a su tiempo. Elisa, entre otras muchas cosas, pudo librarse de las trabas morales que le impedían disfrutar de su sexualidad. Finalmente, María Luisa pudo exigir una mejor 
distribución de las tareas domésticas y así disfrutar finalmente de sus hijos a la par que encontraba espacio para vivir su propia vida.

A medida que se fue desarrollando el modelo de mujer trabajadora se fue consolidando también la doble jornada de las mujeres. No se trata de que hasta entonces las mujeres no tuvieran que trabajar dentro y fuera de casa, lo que ocurre es que a partir de la década de los sesenta se fue tolerando de manera progresiva la entrada de mujeres en trabajos profesionalizados. Esta profesionalización fue en aumento y a las mujeres se les exigía una doble invisibilidad, es decir, que fueran completamente amas de casa y completamente profesionales. Con el incremento en la entrada de las mujeres en las universidades en la década de los setenta y sobre todo a partir de los ochenta el modelo de la mujer trabajadora se fue sustituyendo por el de la supermujer, una mujer aún más cualificada laboralmente. A pesar del progresivo acceso de las mujeres a diversos sectores y de una mayor participación masculina en el reparto de tareas, se puede decir que el franquismo logró consagrar a la mujer como ente fundamentalmente doméstico, premisa que con matices se mantiene hoy en día. Las mujeres siguen siendo las mayores responsables del cuidado de niños, de ancianos y de todo lo concerniente al mantenimiento de la casa. Lejos de conseguirse un verdadero reparto equitativo de las tareas, en ocasiones estas madres de familia, ante la pasividad de sus parejas y de un Estado que elude su responsabilidad con respecto a los más dependientes, delegan parte de las obligaciones que tradicionalmente se les han asignado en otras mujeres, en situación generalmente precaria, que contratadas por horas vienen a sustituirlas. De esta manera, las discusiones familiares, lejos de solucionarse, se taponan a través de la contratación de trabajadoras domésticas. La madre de familia puede mantener su profesionalidad pero, para mantener su visibilidad en el mundo laboral, otra mujer se vuelve invisible entre el mercado sumergido y el trabajo invisible del hogar.

\section{Referencias bibliográficas}

AGUADO, Ana: «La historia de las mujeres como historia social», en María Isabel

Del Val et al. (coords.): La historia de las mujeres: una revisión historiográfica, Valladolid, Universidad de Valladolid, 2004, pp. 57-71.

Andreu Miralles, Xavier, «Y no la de Mèrimeè...: el mito romántico de España

y la identidad nacional española», Comunicación presentada en el I Encuentro de Jóvenes Investigadores en Historia Contemporánea de la AHC, Zaragoza, 26-28 septiembre 2007.

BORDERíAs, Cristina. Entre líneas, trabajo e identidad femenina en la España Contemporánea: la compañía Telefónica, 1924-1980. Barcelona, Icaria, 1993. 
Dios FERnÁNDEZ, Eider de. «Perfiles de las Trabajadoras de Hogar en el Desarrollismo Vizcaíno», Comunicación presentada en el X Congreso de la Asociación de Historia Contemporánea, Santander 16-17 de septiembre de 2010, publicación en CD.

— «Las que tienen que servir» y las servidas. La evolución del servicio doméstico en el franquismo y la construcción de la subjetividad femenina». Revista Historia Autónoma 3 (2013), pp. 97-111.

FRANCO, Rosario. ¿Eternas menores? Las mujeres en el franquismo. Biblioteca Nueva, Madrid, 2007.

GILMORE, David D. «Men and women in Sothern Spain: "Domestic Power" Revisited», en America Anthropological Association, New Series, 92-4 (1990), pp. 953-970.

IgLESIAS HERnÁNDEZ, María Luisa: «El ama de casa y el espíritu de sacrificio en el franquismo», en Laura Benadiba (comp.): Historia oral: fundamentos metodológicos para reconstruir el pasado desde la diversidad, Rosario, SurAmérica ediciones, 2010, pp. 253-269.

Llona, Miren. Entre señorita y garçonne. Historia oral de las mujeres bilbainas de clase media (1919-1939), Málaga, Universidad de Málaga, 2002.

- «Memoria e identidades. Balance y perspectivas de un nuevo enfoque historiográfico», en Cristina Borderías (coord.): La historia de las mujeres: perspectivas actuales, Icaria, Barcelona, 2009, pp. 355-390.

MANRIQUE ARRIBAS, Juan Carlos, «La familia como medio de inclusión de la mujer en la sociedad franquista $»$. Hispania Nova 7 (2007).

MARTín GAITE, Carmen. Usos amorosos de la postguerra española, Barcelona, Anagrama, 1987.

MARTINA Rodríguez, Ma Victoria y RodríGUEz GALlARdo, Ángel, «De compromisos e igualdades. Historia y sociopolítica de las mujeres universitarias gallegas durante el franquismo», Comunicación presentada en el VIII Encuentro Internacional de Investigadores del Franquismo, celebrado en Barcelona el 21 y 22 de noviembre de 2013.

Molinero, Carme. «Silencio e invisibilidad: la mujer durante el primer franquismo». Revista de Occidente 224 (2000), pp. 63-82.

MorCILlo, Aurora. «Españolas con, contra, bajo, (d)el franquismo», en V.V.A.A.: Desacuerdos. Sobre arte, políticas y esfera pública en el Estado español, vol. 7, 2012, pp. 42-63.

— «El género en lo imaginario. «El "ideal católico femenino" y estereotipos sexuados bajo el franquismo», en Mary Nash (ed.): Represión, resistencias, memoria. Las mujeres bajo la dictadura franquista, Granada, Comares Historia, 2013, pp.71-90. 
MuÑoz Ruiz, María del Carmen. Mujer mítica, mujeres reales: las revistas femeninas en España 1955-1970, tesis doctoral, Universidad Complutense de Madrid, 2002.

- «La construcción de las relaciones de género en el franquismo y sus conflictos. Los consultorios sentimentales», Arenal 10-2 (2003), pp. 219-239.

MurILlo ACED, Irene. En defensa de mi hogar y mi pan. Estrategias femeninas de resistencia civil y cotidiana en la Zaragoza de posguerra, 1936-1945. Zaragoza, Prensas universitarias de Zaragoza, 2013.

OFER, Inbal, Señoritas in blue. The making of a female political elite in Franco's Spain, Sussex, Brighton, 2010,

PIÉROLA, Gemma. «Aspectos del discurso moral de la Iglesia sobre la población femenina navarra en el Franquismo». Gerónimo de Uztariz, 16 (2000), pp. 43-55.

Rebollo EsPinosa, María José y NúÑEz Gil, Marina. «Tradicionales, rebeldes, precursoras: instrucción y educación de las mujeres españolas a través de la prensa femenina (1900-1970)», Historia de la educación. 26 (2007), pp. 181-219.

RISUEÑO JURADO, Virginia: «La maternidad vista a través de las imágenes de los manuales escolares. El caso de España, Francia y Holanda (1901-1940)», en Gloria A. Franco Rubio (ed.): Debates sobre la maternidad desde una perspectiva histórica (siglos XVI-XX), Barcelona, Icaria, 2010, pp.127-145.

Roca I GIRONA, Jordi. De la pureza a la maternidad, la construcción del género femenino en la posguerra española, Madrid, Ministerio de Educación y Cultura, 1996.

RODRíGuez LóPEZ, Sofía. El patio de la cárcel. La Sección Femenina de FET-JONS en Almería, 1937-1977. Almería, Centro de Estudios Andaluces, 2010.

VAllÉS AMORES, María Luisa. «La posición jurídica de la mujer a través de las reformas del derecho de familia», Feminismo/s 8, (2006), pp. 115-130. 